\title{
Comparative Results of External Fixation, Plating, or Nonoperative Management for Diaphyseal Clavicle Fractures
}

\author{
Barış Özkul Mehmet Selçuk Saygılı Yaşar Mahsut Dinçel Ilhan Avni Bayhan \\ Deniz Akbulut Bilal Demir
}

Department of Orthopaedic Surgery and Traumatology, Metin Sabanci Baltalimani Bone Disease Training and Research Hospital, Istanbul, Turkey

\section{Significance of the Study}

- This study showed that both plate and external fixator treatment achieved better functional outcomes than conservative methods in patients with displaced clavicular fractures. Hence, external fixation could be considered as a good alternative for the surgical management of clavicular fractures.

\section{Keywords}

Clavicle fracture $\cdot$ External fixator $\cdot$ Malunion .

Osteosynthesis

\begin{abstract}
Objective: The aim of this study was to compare the treatment outcomes of mid-diaphyseal clavicular fractures between an external fixator and more widely selected treatment options such as plate osteosynthesis or conservative methods. Materials and Methods: The medical records of 64 patients who were treated for mid-diaphyseal clavicular fracture in our clinic from 2009 to 2013 were reviewed. The inclusion criterion was mid-diaphyseal closed clavicular fractures with shortening of more than $2 \mathrm{~cm}$. The Constant and DASH (disabilities of the arm, shoulder, and hand) scores at the final follow-up, initial displacement, nonunion, and complication rates were compared. Statistical differences between groups were assessed with the Kruskal-Wallis test, and pairwise comparison analysis was used to evaluate the differ-
\end{abstract}

\section{KARGER}

E-Mail karger@karger.com www.karger.com/mpp
This is an Open Access article licensed under the Creative Common Attribution-NonCommercial-4.0 International License (CC BY-NC) (http://www.karger.com/Services/OpenAccessLicense), applicable to the online version of the article only. Usage and distribution for commercial purposes requires written permission. ences within the groups. Results: Of the 64 patients, 24 $(37.5 \%)$ were treated with plate osteosynthesis (group 1), 11 (17.2\%) with an external fixator (group 2), and 29 (45.3\%) conservatively with a figure-of-eight bandage (group 3). The mean follow-up periods were as follows: group 1: $37 \pm 10.4$ months, group 2: $33 \pm 7$ months, and group 3: $35 \pm 9.4$ months. The initial amount of displacement and DASH score were: group 1: $89.1 \pm 7.8$, group 2: $89.1 \pm 7.8$, and group 3: $6.1 \pm 6.6)(p=0.079)$. The Constant score of group $2(93 \pm 6.1)$ was significantly higher than that of group $3(85 \pm 8.4)(p=$ $0.013)$. No statistical difference was found in the distribution of nonunions ( $p=0.387$ ). However, in group 3 , the number of malunions $(11 / 29,37.9 \%)$ was significantly higher compared to the other 2 groups (group 1: 1/24, 4.2\%; group 2: $2 / 11,18.2 \%)(p=0.006)$. Conclusions: This study revealed that the treatment of acute clavicular fractures with an external fixator was a good alternative to plate osteosynthesis or conservative treatment.

(c) 2017 The Author(s) Published by S. Karger AG, Basel 


\section{Introduction}

Clavicular fractures make up $2-5 \%$ of all fractures, and $70 \%$ involve the mid-diaphyseal region [1-3]. Lateral and medial end fractures of the clavicle are seen less frequently and the treatment forms are different [3-6]. In many previous studies, shortening of $2 \mathrm{~cm}$ or more was mentioned as an indication for surgery for mid-diaphyseal clavicular fractures.

The majority of mid-diaphyseal clavicular fractures are treated conservatively [7-9]. However, several studies in the literature have emphasized complications such as malunion, nonunion, and reduced shoulder functional capacity $[6,7]$. Although the functional results are better in anatomically reduced fractures applied with plate osteosynthesis, complications of this method have also been reported, such as infection, wound site scars, and implant irritation $[5,7,9]$. Previous reports have shown that the application of an external fixator to the clavicle is a preferred option for the treatment of nonunion and open fractures $[8,10]$. A study by Shukla et al. [5] reported that they successfully applied external fixator treatment in acute clavicle fractures and achieved union at the appropriate position for all patients. Schuind et al. [11] also reported successful application of external fixator treatment in 5 multitrauma patients. Nonunion, malunion, and related cosmetic and functional complications that have been reported can be prevented by external fixator treatment $[5,11]$.

The basic reasons for the selection of fixation with an external fixator for the patients in the current study were to eliminate the disadvantages of conservative treatment and to reduce the surgical risks of the open reduction and plate fixation method. The aim of this study was to compare clavicular fracture treatment outcomes between external fixator treatment and more widely selected treatment options such as plate osteosynthesis or conservative methods.

\section{Materials and Methods}

The medical records of 87 patients who were treated for clavicular fracture in our clinic between 2009 and 2013 were reviewed. Exclusion criteria were incomplete records, bilateral medial third, lateral end, or open fractures, multitrauma, age $<14$ years or $>65$ years, and time from fracture to treatment $>21$ days. Based on these criteria, 24 patients were excluded. The remaining 64 patients were included in the study based on a mid-diaphyseal closed fracture and shortening of $2 \mathrm{~cm}$ or more in the fracture ends. The choice of surgical treatment method was based on the surgeon's preferences.

Comparative Treatment Options for

Clavicle Fractures
Constant [12] and DASH (disabilities of the arm, shoulder, and hand) scores [13] at the final follow-up examination, the amount of shortness in the clavicle, the initial displacement amount, the time to full functional use, and skin irritation were obtained from the medical records.

The radiographs taken during follow-up examinations of the patients were evaluated by a single researcher (B.Ö.) on a screen using a digital method on the Infinitt PACS system (Infinitt Healthcare Co., Seoul, South Korea). The time to union and the amount of shortness compared to the contralateral clavicle were evaluated on the radiographs. At the last follow-up, the presence of pain and/or absence of radiographic findings of callus in the clavicle were accepted as nonunion. The presence of bridging callus in at least 3 anatomic planes on the control radiographs was considered as a union. Patients with inadequate healing were evaluated with computed tomography. After union, shortening of more than $2 \mathrm{~cm}$ and/or skin irritation due to angulation defects were accepted as a malunion.

\section{External Fixator Surgical Technique}

The patients were positioned supine with a silicone cushion below the scapula. After sterile draping, the areas in the proximal and distal main fragments of the clavicle where the pins were to be placed were marked with the tip of an injector. For the medial and lateral fragments, a total of 4 (as 2 pairs) of 3-mm Schanz screws were placed according to the distant-distant and close-close principle. The fragments were evaluated under fluoroscopic imaging to avoid posterior migration of the screws. Using the applied screws as a joystick, under image intensifier guidance, first the pins close to the fracture line and then the distant pins were fixed with a trauma-type pin to bar fixator rods. Finally, by fixing these rods with a third rod, stability was increased. Fluoroscopic images were taken to check the procedure (Fig. 1). When bridging callus was observed in at least 3 anatomic planes the external fixator was removed immediately in the clinic without any complications.

\section{Plate Osteosynthesis Surgical Technique}

After the patients were placed in the beach chair position on the operating table, sterile surgical covering was done. An oblique incision of approximately $7-10 \mathrm{~cm}$ was performed. Care was given to the supraclavicular nerve, which was protected throughout the procedure. Fracture reduction was performed with bone fixation clamps. After confirmation of satisfactory reduction using fluoroscopy, fixation was achieved with a $3.5-\mathrm{mm}$ anatomic plate and screws.

\section{Conservative Treatment Method}

Conservative treatment of the patients in the study was done with either figure-of-eight bandages or standard slings. In the literature, there is no radiological or functional difference between the 2 methods $[14,15]$. After 3 weeks of treatment, active shoulder range-of-motion exercises were initiated to increase the functional capacity and strength of the patients in the early period.

\section{Statistical Analysis}

Statistical analysis was done using SPSS 15.0 software (Statistics Program for Social Sciences; SPSS Inc., Chicago, IL, USA). Normality of the distribution of variables was tested with the Kolmogorov-Smirnov test. For the evaluation of categorical variables between groups (Constant score, Dash score, full function use,

Med Princ Pract 2017;26:458-463 
Fig. 1. A mid-shaft clavicle fracture. a Patient in a supine position. b Proximal and distal fragments marked with the tip of an injector. c Placement of 4 Schanz screws. d After the reduction trauma-type fixator was fixed.
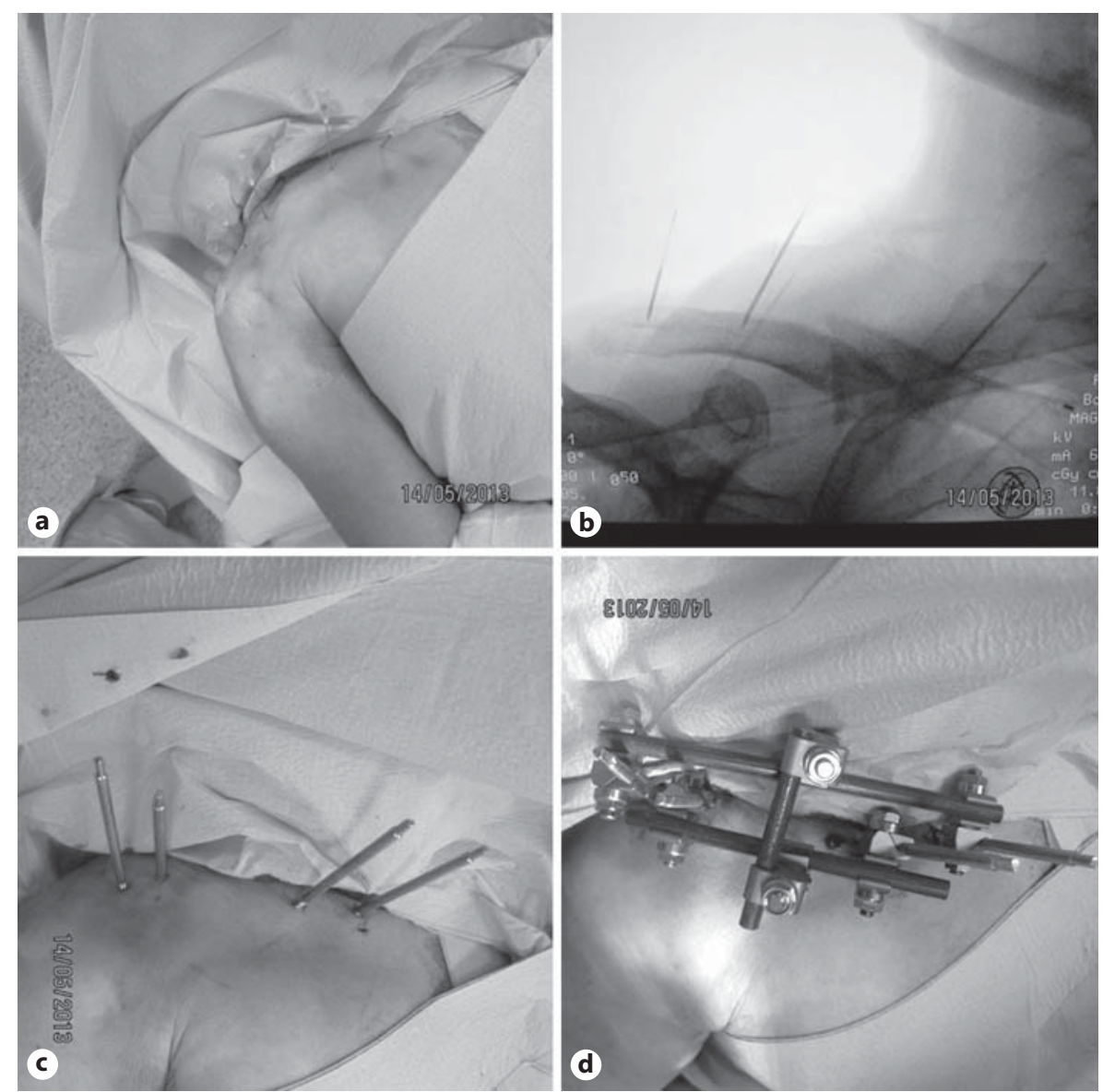

union time), the Kruskal-Wallis test was used. A pairwise comparison test was used to evaluate the differences in each group. The distribution of nonunion and malunion was assessed with the Fisher exact test. A $p$ value $<0.05$ was considered to be statistically significant.

\section{Results}

Of the 64 patients, 24 (37.4\%; 18 males, 6 females) were treated with plate osteosynthesis (group 1), 11 (17.2\%; 8 males, 3 females) were treated with an external fixator, and 29 (45.3\%; 25 males, 4 females) were treated conservatively with a figure-of-eight bandage. The corresponding mean age of the patients was of $28.5 \pm 8.5,31 \pm 12.8$, and $31 \pm 12.8$ years. The demographic data of the patients including age, gender, cigarette smoking status, affected side, and follow-up duration are presented in Table 1.

The mean follow-up periods were: group 1: $37 \pm 10.4$ months, group 2: $33 \pm 7$ months, and group 3: $35 \pm 9.4$ months. On the preoperative radiographs, the length of displacement was as follows: group 1: $2.4 \pm 0.5 .7 \mathrm{~cm}$, group 2: $2.4 \pm 0.5 .6 \mathrm{~cm}$, and group 3: $2.3 \pm 0.6 \mathrm{~cm}$. Based on fracture type, in group 1 (24 patients), 13 (54\%) were simple fractures, $8(33 \%)$ wedge, and $3(12 \%)$ complex. In group 2 (11 patients), 3 (27\%) were simple fractures, 5 (45\%) wedge, and $3(27 \%)$ complex. In group 3 (29 patients), 18 (62\%) were simple fractures, 8 (27\%) wedge, and $3(10 \%)$ complex.

No statistically significant difference was found between the groups regarding the initial amount of displacement of diaphyseal clavicle fracture prior to surgery $(p=0.803)$, gender $(p=0.54)$, age $(p=0.244)$, duration of follow-up $(p=0.755)$, DASH score $(p=0.079)$, and week of radiological union $(p=0.283)$.

In the Kruskal-Wallis test, there was a statistically significant difference between the groups regarding the Constant score (group 1: $89.1 \pm 7.8$, group 2: $93 \pm 6.1$, group 3: $85 \pm 8.4)(p=0.014)$ and time to full functional use $(p=0.039)$. In the pairwise comparison analysis, when the difference within the group was examined, the Constant score of group $2(93 \pm 6.1)$ was significantly 
Table 1. Demographic data of the patients

\begin{tabular}{|c|c|c|c|c|c|c|c|c|c|c|}
\hline & \multicolumn{2}{|l|}{ Age, years } & \multicolumn{2}{|c|}{ Follow-up, months } & \multicolumn{2}{|c|}{$\begin{array}{l}\text { Amount of } \\
\text { displacement, } \mathrm{cm}\end{array}$} & \multirow[t]{2}{*}{$\begin{array}{l}\text { Patients } \\
(\mathrm{F} / \mathrm{M}), n\end{array}$} & \multirow[t]{2}{*}{$\begin{array}{l}\text { Right/left } \\
\text { side, } n\end{array}$} & \multirow[t]{2}{*}{$\begin{array}{l}\text { Dominant } \\
\text { side, } n\end{array}$} & \multirow[t]{2}{*}{$\begin{array}{l}\text { Smo- } \\
\text { kers, } n\end{array}$} \\
\hline & mean $\pm S D$ & $\begin{array}{l}\text { median } \\
\text { (range) }\end{array}$ & mean \pm SD & $\begin{array}{l}\text { median } \\
\text { (range) }\end{array}$ & mean $\pm \mathrm{SD}$ & $\begin{array}{l}\text { median } \\
\text { (range) }\end{array}$ & & & & \\
\hline \multicolumn{11}{|l|}{ Group 1} \\
\hline (plate osteosynthesis) & $28.5 \pm 8.5$ & $27.5(16-44)$ & $37 \pm 10.4$ & $32.5(24-61)$ & $2.4 \pm 0.5 .7$ & $2(2-4.2)$ & $24(18 / 6)$ & $14 / 10$ & 15 & 11 \\
\hline \multicolumn{11}{|l|}{ Group 2} \\
\hline (external fixator) & $31 \pm 12.8$ & $28(14-52)$ & $33 \pm 7$ & $33(25-46)$ & $2.4 \pm 0.5 .6$ & $2(2-3.5)$ & $11(8 / 3)$ & $15 / 6$ & 5 & 3 \\
\hline \multicolumn{11}{|l|}{ Group 3} \\
\hline (conservative treatment) & $34 \pm 12.3$ & $33(16-61)$ & $35 \pm 9.4$ & $35(23-55)$ & $2.3 \pm 0.6$ & $2(2-4)$ & $29(25 / 4)$ & $14 / 15$ & 18 & 9 \\
\hline
\end{tabular}

Table 2. Statistical results of functional evaluations

\begin{tabular}{|c|c|c|c|c|c|c|c|}
\hline \multirow[t]{2}{*}{ Variables } & \multicolumn{2}{|c|}{ Group 1 (plate osteosynthesis) } & \multicolumn{2}{|c|}{ Group 2 (external fixation) } & \multicolumn{2}{|c|}{ Group 3 (conservative) } & \multirow[t]{2}{*}{$p$ value } \\
\hline & mean $\pm \mathrm{SD}$ & median (range) & mean $\pm S D$ & median (range) & mean \pm SD & median (range) & \\
\hline Constant score & $89.1 \pm 7.8$ & $90(70-98)$ & $93 \pm 6.1$ & $96(80-98)$ & $85 \pm 8.4$ & $87(63-98)$ & 0.014 \\
\hline DASH score & $4.6 \pm 3.7$ & $3.05(1.7-14.2)$ & $2.1 \pm 1.9$ & $2(0-7)$ & $6.1 \pm 6.6$ & $3.3(0-25)$ & 0.079 \\
\hline Full functional use, months & $4 \pm 1.06$ & $4(2-6)$ & $5.09 \pm 1.13$ & $5(3-7)$ & $4.8 \pm 1.5$ & $5(3-7)$ & 0.039 \\
\hline Union time, weeks & $9 \pm 2.6$ & $8(6-15)$ & $9 \pm 2.6$ & $11(4-14)$ & $10 \pm 3.3$ & $11(6-17)$ & 0.283 \\
\hline Nonunion, $n$ & $1 / 24(4 \%)$ & & 0/11 (0\%) & & $4 / 29(13 \%)$ & & 0.387 \\
\hline Malunion, $n$ & $1 / 24(4 \%)$ & & $2 / 11(18 \%)$ & & $11 / 29(37 \%)$ & & 0.006 \\
\hline
\end{tabular}

higher than that in group $3(85 \pm 8.4)(p=0.013)$. With respect to the time to full functional use, although the within-group significance was low $(p=0.015)$, group 1 time ( $4 \pm 1.06$ months) was seen to be significantly lower than that of group $2(5.09 \pm 1.13$ months $)(p=0.039)$. While no statistically significant difference was seen between the groups with respect to rates of nonunion ( $p=$ 0.387 ), the number of malunion patients in group 3 was significantly higher compared to the other 2 groups ( $p=$ 0.006 ) (Table 2). Skin irritation was determined in 9 $(37 \%)$ of the patients treated with plate osteosynthesis and $10(34 \%)$ of the conservatively treated patients. In group 1, 5 (20\%) patients had the implant removed due to plate irritation, and $2(8 \%)$ patients due to wound site problem. Patients did not develop deep infection-osteomyelitis. Three $(27 \%)$ patients with an external fixator had superficial pin site infection that was treated with oral antibiotics. No cosmetic complaints due to scarring or malunion were found in or reported by patients with an external fixator (Fig. 2). No postoperative refracture was seen in any of the groups. Two patients who had nonunion in group 3 were treated with plate osteosynthesis with autograft. Malunion required 4 corrective osteotomies, but the patients did not accept this treatment.

Comparative Treatment Options for Clavicle Fractures

\section{Discussion}

In this study, the 3 different treatment methods of clavicular diaphyseal fractures revealed similar good outcomes in radiological union time and DASH scores. However, the Constant score and the malunion rate had better outcomes in the surgical treatment groups than with the conservative method, which was consistent with previous studies [5, 16-18].

In the present study, the time to full functional use in the external fixator group was significantly greater than that in the plate osteosynthesis group, which could be due to the discomfort effect of the external fixator applied during the treatment period. This can also be explained by the achievement of similar functional scores in both of the surgically treated groups after the removal of the external fixator.

In this study, although no statistically significant difference was found between the groups regarding nonunion, a significant number of malunion cases occurred in the conservative treatment group, which was consistent with previous studies $[5,17,19]$. However, in a multicenter, randomized, controlled study, the number of malunion and nonunion cases were statistically significantly higher in the group with conservative treatment

Med Princ Pract 2017;26:458-463 461 

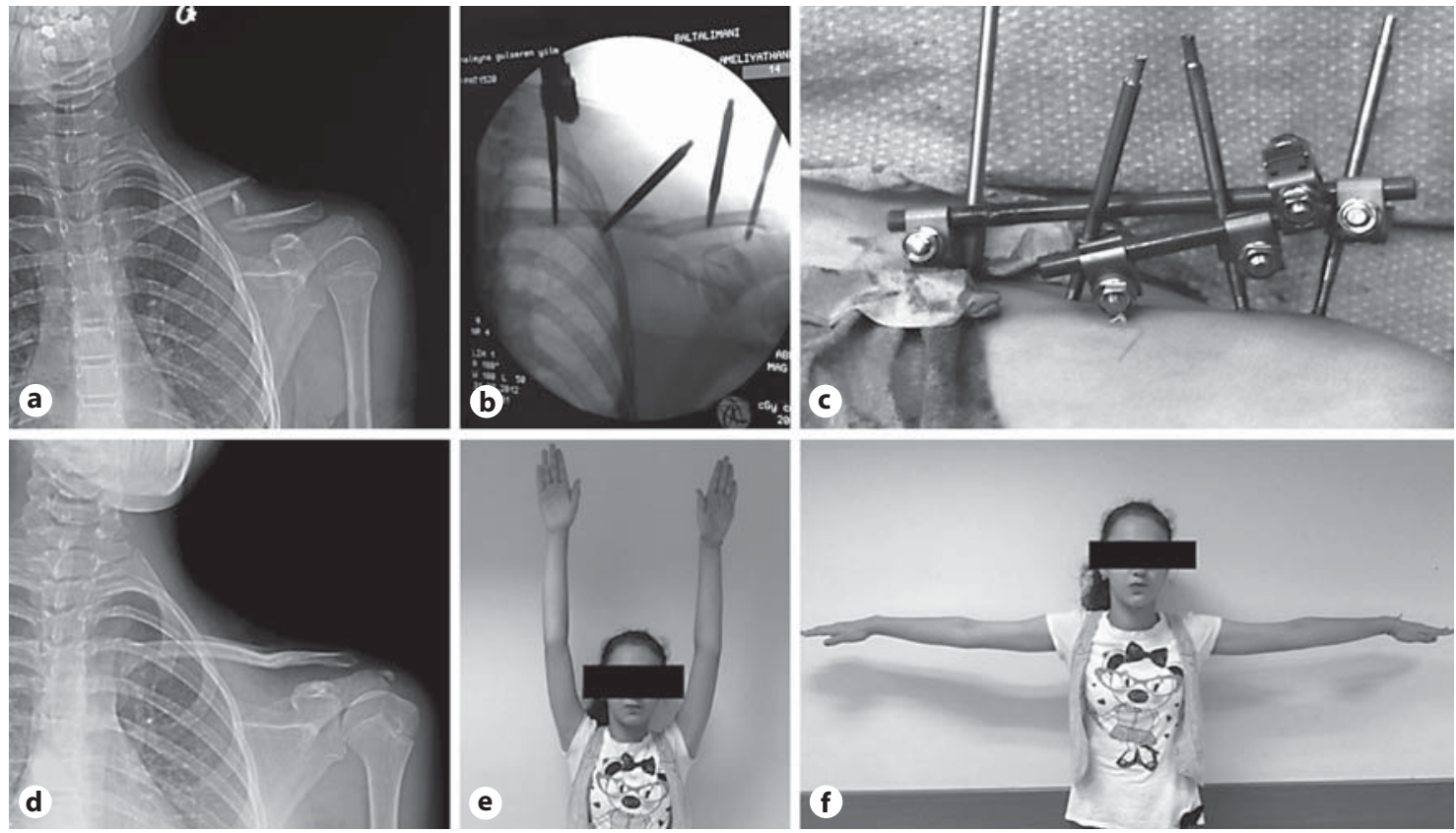

Fig. 2. A mid-shaft clavicle fracture. a Preoperative radiography. b Fluoroscopic image. c Trauma-type fixator fixed. $\mathbf{d}$ Late postoperative radiography. e, $\mathbf{f}$ Good functional outcome at final follow-up.

compared to the osteosynthesis group [1]. There are studies in the literature which have reported that clinical results are negatively affected by shortening of $>2 \mathrm{~cm}$ or $>10-13 \%$ reduction after treatment compared to the contralateral clavicle $[1,5,6,20,21]$. In the current study, when there was malunion after conservative treatment, there was a significant reduction in the Constant score compared to the other groups, but this did not prevent full functional use of the extremity. The anatomical arrangement provided by surgery solved the cosmetic dissatisfaction associated with malunion.

In the current study, implant irritation was found in $37 \%$ of the patients treated with plate osteosynthesis, and 5 patients had to undergo plaque removal due to irritation. In the literature, the most common complications of plate osteosynthesis in the clavicular fracture have been hypertrophic scar tissue, implant irritation, and implantrelated infection $[2,6,16,18]$. On the other hand, pin site infection is another problem after external fixator surgery. In our study, no cosmetic complaints related to the fixator pin entry sites were reported or found in group 2 , except in 3 patients, who had superficial pin site infection that responded to oral antibiotic treatment. In the literature, after external fixator pin site infections, pin loosening, implant instability, and osteomyelitis developed at rates of $4-10 \%[22,23]$. It is thought that the external fixator was removed immediately after the 3 anatomic planes of the bridging callus were seen, and that this procedure could have protected the patients from the complications of pin site infection. This study showed that the treatment of acute close clavicular fracture with an external fixator can avoid the complication risks associated with plate osteosynthesis with similar functional results.

The limitations of the current study include its retrospective nature, the lack of cost analysis for the different treatment methods, the low number of patients in the external fixator group, and the fact that more than one surgeon performed the operations in the plate osteosynthesis group.

\section{Conclusion}

This study revealed that the surgical treatment of acute clavicular fractures with an external fixator was a good alternative to plate osteosynthesis, and that surgical treatment was better than conservative treatment, in clavicular fractures with more than $2 \mathrm{~cm}$ displacement. Hence, external fixation in the surgical treatment of clavicular fractures could be considered as a good alternative. 


\section{References}

1 Canadian Orthopaedic Trauma S: Nonoperative treatment compared with plate fixation of displaced midshaft clavicular fractures. A multicenter, randomized clinical trial. J Bone Joint Surg Am 2007;89:1-10.

2 Jiang H, Qu W: Operative treatment of clavicle midshaft fractures using a locking compression plate: comparison between miniinvasive plate osteosynthesis (MIPPO) technique and conventional open reduction. Orthop Traumatol Surg Res 2012;98:666671.

3 Sokucu S, Menges O, Cetinkaya E, et al: Treatment of comminuted mid-diaphyseal clavicle fractures by plate fixation using a bridging technique. Acta Orthop Traumatol Turc 2014;48:401-405.

4 Chalidis B, Sachinis N, Samoladas E, et al: Acute management of clavicle fractures. A long-term functional outcome study. Acta Orthop Belg 2008;74:303-307.

5 Shukla A, Sinha S, Yadav G, et al: Comparison of treatment of fracture midshaft clavicle in adults by external fixator with conservative treatment. J Clin Orthop Trauma 2014;5:123128.

6 Postacchini R, Gumina S, Farsetti P, et al: Long-term results of conservative management of midshaft clavicle fracture. Int Orthop 2010;34:731-736.

7 Sohn H-S, Shon MS, Lee K-H, et al: Clinical comparison of two different plating methods in minimally invasive plate osteosynthesis for clavicular midshaft fractures: a randomized controlled trial. Injury 2015;46:2230-2238.
8 Barlow T, Upadhyay P, Barlow D: External fixators in the treatment of midshaft clavicle non-unions: a systematic review. Eur J Orthop Surg Traumatol 2014;24:143-148.

9 Zhang Y, Xu J, Zhang C, et al: Minimally invasive plate osteosynthesis for midshaft clavicular fractures using superior anatomic plating. J Shoulder Elbow Surg 2016;25:e7e12.

10 Demiralp B, Atesalp AS, Sehirlioglu A, et al: Preliminary results of the use of Ilizarov fixation in clavicular non-union. Arch Orthop Trauma Surg 2006;126:401-405.

11 Schuind F, Pay-Pay E, Andrianne Y, et al: External fixation of the clavicle for fracture or non-union in adults. J Bone Joint Surg Am 1988;70:692-695.

12 Constant CR, Murley AH: A clinical method of functional assessment of the shoulder. Clin Orthop Relat Res 1987;160-164.

13 Hudak PL, Amadio PC, Bombardier C: Development of an upper extremity outcome measure: the DASH (disabilities of the arm, shoulder and hand) (corrected). The Upper Extremity Collaborative Group (UECG). Am J Ind Med 1996;29:602-608.

14 Ersen A, Atalar AC, Birisik F, et al: Comparison of simple arm sling and figure of eight clavicular bandage for midshaft clavicular fractures: a randomised controlled study. Bone Joint J 2015;97-B:1562-1565.

15 Andersen K, Jensen PO, Lauritzen J: Treatment of clavicular fractures. Figure-of-eight bandage versus a simple sling. Acta Orthop Scand 1987;58:71-74.
16 Millett PJ, Hurst JM, Horan MP, et al: Complications of clavicle fractures treated with intramedullary fixation. J Shoulder Elbow Surg 2011;20:86-91.

17 McKee RC, Whelan DB, Schemitsch EH, et al: Operative versus nonoperative care of displaced midshaft clavicular fractures: a metaanalysis of randomized clinical trials. J Bone Joint Surg Am 2012;94:675-684.

18 Kulshrestha V, Roy T, Audige L: Operative versus nonoperative management of displaced midshaft clavicle fractures: a prospective cohort study. J Orthop Trauma 2011;25: 31-38.

19 Hillen RJ, Burger BJ, Poll RG, et al: Malunion after midshaft clavicle fractures in adults. Acta Orthop 2010;81:273-279.

20 Hill JM, McGuire MH, Crosby LA: Closed treatment of displaced middle-third fractures of the clavicle gives poor results. J Bone Joint Surg Br 1997;79:537-539.

21 Nowak J, Holgersson M, Larsson S: Sequelae from clavicular fractures are common: a prospective study of 222 patients. Acta Orthop 2005;76:496-502.

22 Tekin AC, Saygili MS, Adas M, et al: Outcome of type 3 open tibial diaphyseal fractures managed with a limb reconstruction system: analysis of a 49-patient cohort. Med Princ Pract 2016;25:270-275.

23 Kazmers NH, Fragomen AT, Rozbruch SR: Prevention of pin site infection in external fixation: a review of the literature. Strategies Trauma Limb Reconstr 2016;11:75-85.
Comparative Treatment Options for Clavicle Fractures
Med Princ Pract 2017;26:458-463

DOI: $10.1159 / 000481865$ 